\title{
Анализ свойств пленок молекулярно-импринтированных полимеров на основе полиимида
}

\author{
(C) 2021 Ву Хоанг Иен ${ }^{1,2}$, Као Ньят Линь ${ }^{3}$, Зяблов А.Н. ${ }^{1}$ \\ ${ }^{I}$ ФГБОУ «Воронежский государственный университет», Воронеж \\ ${ }^{2}$ Пищевой Промышленный Университет Хочимина, Вьетнам \\ ${ }^{3}$ Приморское отделение, Совместный Российско-Вьетнамский тропический научно-исследователь- \\ ский и технологический центр, Вьетнам
}

Поступила в редакцию 28.03.2021 г.

DOI: $10.17308 /$ sorpchrom.2021.21/3469

В работе получены молекулярно-импринтированные полимеры на основе сополимера диангидрида 1,2,4,5-бензолтетракарбоновой кислоты и 4,4'-диаминодифенилоксида и раствора консервантов (2:1). Исследование свойств пленок молекулярно-импринтированных полимеров (МИП) проводили методом инфракрасной спектроскопии и сканирующей силовой микроскопии (ССМ).

Установлено, что в ИК-спектрах МИП и полимеров сравнения отсутствуют существенные различия. Это означает, что при синтезе молекулярно-импринтированных полимеров «лестничная» структура, характерная для полиимида сохраняется, но при этом увеличивается интенсивность характеристических частот для полимеров с отпечатками консервантов.

Анализ морфологии поверхности пленок показал, что нанесение предполимеризационной смеси штампом приводит к формированию более равномерной поверхности (с перепадом высот от 1.4 до 2.6 нм) чем в случае, когда смесь наносили шпателем (с высотами в диапазоне 0.9-4.0 нм). Отработанная методика нанесения смеси штампованием позволяет получать пленки с хорошей воспроизводимостью толщины и морфологии поверхности.

Сравнение ССМ-изображений молекулярно-импринтированных полимеров и полиимида, на основе которого они получены, выявило уменьшение количества микро- и увеличение количества мезопор. При этом морфология пленок МИП-Е202 и МИП-Е211 имеет существенные отличия, связанные с особенностями формирования отпечатков сорбата калия и бензоата натрия.

При синтезе МИП-Е211 образуется значительное количество мезо- и макропор. С учетом малого размера молекулы бензоата натрия (0.82 нм), можно предположить, что внутренние поверхности мезо- и макропор полимерной пленки могут содержать углубления и поры (отпечатки) комплементарные молекулам бензоата натрия. В случае с сорбатом калия, имеющего линейную структуру, его молекулы располагаются как на поверхности, так и заглубляются в матрицу полимера. При их удалении остаются отпечатки, которые составляют большую часть поверхности и соответствуют размерам ультрамикро- и микропор.

Проведенные исследования ССМ-изображений пленок молекулярно-импринтированных полимеров выявили отсутствие глобул на их поверхности, что свидетельствует о практически полном удалении в процессе экстракции молекул-шаблонов.

Ключевые слова: бензоат натрия, сорбат калия, полиимид, молекулярно-импринтированный полимер (МИП), ИК-спектроскопия, сканирующая силовая микроскопия (ССМ).

\section{Введение}

Пищевые консерванты - это добавки, используемые для предотвращения или замедления гниения, вызванного ростом микробов (дрожжей, плесневых грибов, бактерий и др.) или нежелательными химическими изменениями и тем самым увеличивающие срок хранения этих продуктов [1]. 
В связи с увеличением спроса на пищевые полуфабрикаты использование консервантов для увеличения срока хранения продуктов стало очень популярным. Некоторые консерванты, например, нитраты, нитриты, сахар, соль, сорбиновая кислота, бензойная кислота и их соли широко применяются в пищевых продуктах: в переработанном мясе, в напитках и соленьях, в маргаринах, заправках для салатов, соевом соусе и джемах поскольку обладают эффективным противомикробным свойством [2].

Содержание консервантов в продуктах питания регламентировано Таможенным союзам [3]. Максимальный уровень концентрации в продукции зависит от категории пищевого продукта и установленная доза потребления в день зависит от возрастной группы человека.

В основном консерванты безопасны, однако их избыток в продуктах питания может вызвать аллергические реакции [4]. В частности, бензойная кислота и ее соли считаются аллергенными для чувствительных людей. Бензоат натрия в напитках может взаимодействовать с аскорбиновой кислотой в кислой среде и образовывать некоторое количество бензола. Хотя количество образующегося бензола невелико, но риск появления раковых клеток существует $[5,6]$.

Бензоаты считаются безвредными для человека при допустимых уровнях концентрации, тем не менее в ряде работ [7, 8] показано, что при долгосрочном, а иногда и краткосрочном действии они способны оказывать канцерогенное воздействие на организм человека и вызывать гиперактивность у детей.

Поэтому очень важно контролировать содержание консервантов в пищевых продуктах, что делает актуальным совершенствование имеющихся и разработку новых аналитических методов.

В настоящее время для определения консервантов в пищевых продуктах применяют: спектрофотометрию, газовую хроматографию (ГХ), высокоэффективную жидкостную хроматографию
(ВЭЖХ), тонкослойную хроматографию (TCX) и электрохимические методы анализа. Однако все эти методы не являются универсальными для всего спектра пищевых консервантов, кроме того, при их использовании требуется сложная пробоподготовка, громоздкое и дорогостоящее оборудование, длительное время анализа, а также проведения анализа только в стационарной лаборатории. Поэтому одной из актуальных задач является разработка экспресс-методов анализа, умеющих высокую доступность, чувствительность и избирательность [9].

Для проведения экспресс-анализа все чаще используют пьезосенсоры на основе молекулярно-импринтированных полимеров (МИП). Несмотря на то, что методики синтеза МИП как правило универсальны, тем не менее при получении отпечатков требуется корректировка условий синтеза. В связи с этим целью работы было исследование свойств пленок молекулярно-импринтированных полимеров на основе полиимида с отпечатками бензоата натрия и сорбата калия.

\section{Экспериментальная часть}

Для получения молекулярно-импринтированных полимеров с отпечатками консервантов: бензоат натрия (Е211), сорбат калия (Е202), готовили предполимеризационную смесь, содержащую сополимер диангидрида 1,2,4,5-бензолтетракарбоновой кислоты и 4,4' диаминодифенилоксида (ОАО МИПП НПО «Пластик», Москва), а также консерванты в водно-спиртовом растворе (2:1). Смесь наносили на поверхность пьезосенсора и помещали в сушильный шкаф, в котором проводили двухступенчатую температурную обработку. На первой ступени при температуре $80^{\circ} \mathrm{C}$ в течение одного часа проходило удаление растворителя из полимеризационной смеси. Затем на второй ступени при температуре $180^{\circ} \mathrm{C}$, в течение 30 минут проходил процесс отщепления воды с образованием имидных связей, а также удаление остатков раствори- 
теля. Далее сенсора охлаждали до комнатной температуры, промывали дистиллированной водой и оставляли на 24 часа в дистиллированной воде для удаления шаблона из полимерной пленки. После чего сенсор сушили при $50^{\circ} \mathrm{C}$, в течение 60 минут. В аналогичных условиях, но без добавления шаблона (темплата) получали полимеры сравнения (ПС) [10, 11].

ИК-спектры получали на ИК-спектрометре VERTEX-75 фирмы «Брукер» Германия при следующих условиях: детектор DTGS; светоделитель из Ge-on-KBr; источник Ceramic Source; спектральный диапазон 400-4000 cм-1; разрешение $4 \mathrm{~cm}^{-1}$. Анализ спектров проводили с использованием литературы $[12,13]$.

Для исследования морфологии поверхности полученных полимеров использовали сканирующий силовой микроскоп (CCM) «Solver P47 PRO» производства 3АО «НТ-МДТ». Сканирование образцов проводили в полуконтактном

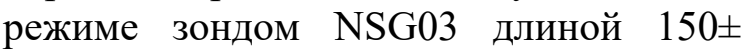
10 мкм, жесткость 1.74 H/м. Обработку реультатов проводили в программе ФемтоСкан-001 [14].

\section{Обсуждение результатов}

В работе были исследованы ИК-спектры полимеров на основе полиимида и молекулярно-импринтированные полимеры с отпечатками сорбата калия и бензоата натрия (рис. 1-2). Характеристические частоты колебаний групп атомов представлены в таблице 1 .

Для всех полимеров появляется минимум пропускания в области 2362$2368 \mathrm{~cm}^{-1}$, относящийся к колебаниям ассоциированных - $\mathrm{COOH}$ групп между карбоксильными группами и иминогруппами в имидогруппировках. Полосы в областях 1730-1690 $\mathrm{cm}^{-1}$ и 1790-1740 $\mathrm{cm}^{-1}$ (симметричные и асимметричные валентные колебания групп $\mathrm{C}=\mathrm{O}$ в имидных циклах) и в областях 1390-1360 см-1 (валентные колебания $\mathrm{C}-\mathrm{N}$ полиимидов) показывают наличие имидных циклов. Для данных полимерных структур, наличие полос поглощения характерно колебание бензольного кольца в областях 1530-1475 $\mathrm{cm}^{-1}$ (скелетные валентные колебания CС связи в бензольном кольце), 1250-950 $\mathrm{cm}^{-1}$ и 900-690 см-1 (плоскостные и внеплоскостные деформационные колебания C--Н связи в бензольном кольце). Для полиимида минимум в областях 1020-890 $\mathrm{cm}^{-1}$ и 750-650 $\mathrm{cm}^{-1}$ характеризует неплоское и внеплоскостное деформационное колебание О-Н связи; полоса в областях $1320-1210 \mathrm{~cm}^{-1}$ соответствует валентным колебаниям $\mathrm{C}-\mathrm{O}$ групп и $\mathrm{Ar}-\mathrm{O}-\mathrm{Ar}$ (в областях 1290-1230 $\left.\mathrm{cm}^{-1}\right)$ [17, 18]. Минимум

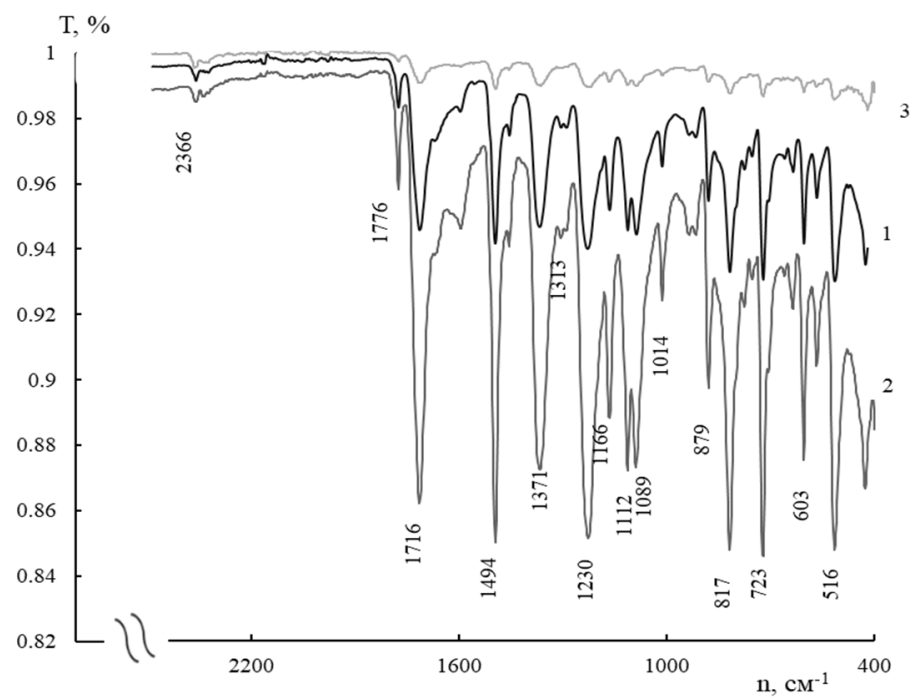

Рис. 1. ИК-спектры полимерных пленок: 1 - полимер сравнения;

2 - полимер с сорбатом калия; 3 - полимер после удаления сорбата калия

Fig. 1. IR spectra of polymer films: 1 - reference polymer; 2 - polymer with potassium sorbate; 3 - polymer after removal of potassium sorbate 


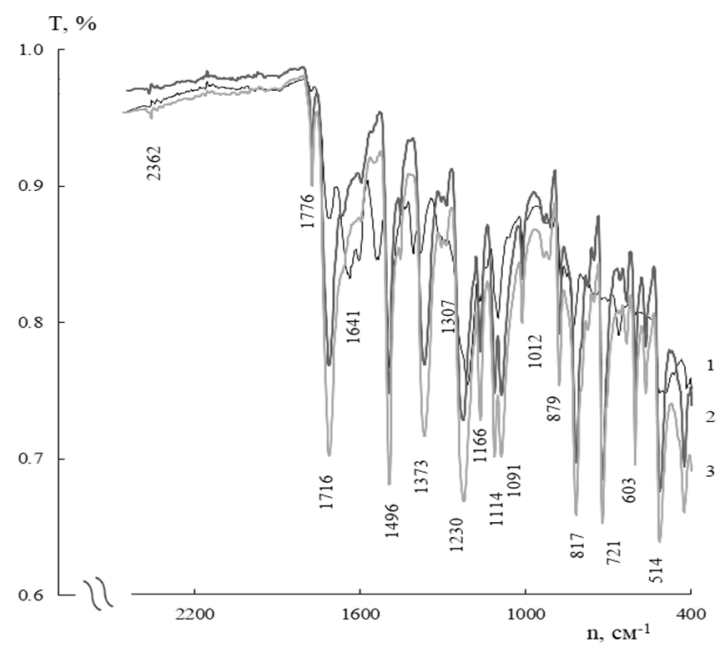

Рис. 2. ИК-спектры полимерных пленок: 1 - полимер сравнения; 2 - полимер с бензоатом натрия; 3 - полимер после удаления бензоата натрия

Fig. 2. IR spectra of polymer films: 1 - reference polymer; 2 - polymer with sodium benzoate; 3 - polymer after removal of sodium benzoate

вблизи $620 \mathrm{~cm}^{-1}$ характеризует деформационные колебания связи $\mathrm{O}=\mathrm{C}-\mathrm{N}$ (амид IV) и связан с взаимодействием валентных колебаний связей $\mathrm{C}-\mathrm{N}$ и $\mathrm{C}=\mathrm{O}$.

Структурно-групповой анализ ИКспектров полимеров показывал, что для МИП и исходных полимеров нет существенных изменений. Это означает, что при синтезе молекулярно-импринтированных полимеров «лестничная» структура [19], характерная для полиимида сохраняется. Но при этом увеличивается интенсивность характеристических частот для полимеров с отпечатками консервантов.

Таблица 1. Характеристические частоты групп атомов в полимерах

Table 1. Characteristic frequencies of groups of atoms in polymers

\begin{tabular}{|c|c|c|c|c|c|c|}
\hline \multirow{2}{*}{$\begin{array}{c}\text { Отнесение колеба- } \\
\text { ний }\end{array}$} & \multicolumn{6}{|c|}{ Частота колебания $v$, cm $^{-1}$} \\
\hline & {$[15,16]$} & ПС & $\Pi C+E 211$ & ПС-Е211 & $\Pi$ ПС+E202 & $\begin{array}{l}\text { ПС- } \\
\text { Е202 }\end{array}$ \\
\hline $\begin{array}{c}\text { Ассоц. } \\
\text { СООН группа }\end{array}$ & $3300-2000$ & 2362 & 2368 & 2362 & 2366 & 2366 \\
\hline$v_{\text {as }} \mathrm{C}=\mathrm{O}$ в имидах & $1790-1740$ & 1776 & 1776 & 1776 & 1776 & 1776 \\
\hline$v_{\mathrm{s}} \mathrm{C}=\mathrm{O}$ в имидах & $1730-1690$ & 1716 & 1716 & 1716 & 1716 & 1716 \\
\hline $\begin{array}{l}\text { Скелетные } v \text { C-Cв } \\
\text { бензольном кольце }\end{array}$ & $1530-1475$ & 1494 & 1496 & 1496 & 1496 & 1496 \\
\hline$v \mathrm{C}-\mathrm{N}$ полиимидов & $1390-1360$ & 1373 & 1373 & 1373 & 1371 & 1369 \\
\hline$v \mathrm{C}-\mathrm{O}$ & $1320-1210$ & 1307 & 1307 & 1307 & 1313 & 1313 \\
\hline$v \mathrm{Ar}-\mathrm{O}-\mathrm{Ar}$ & $1290-1230$ & 1234 & 1232 & 1230 & 1230 & 1232 \\
\hline $\begin{array}{c}\delta_{\text {ip }} \text { C-H в бензоль- } \\
\text { ном кольце }\end{array}$ & $1250-950$ & 1166 & 1166 & 1166 & 1166 & 1166 \\
\hline$\delta \mathrm{C}-\mathrm{C}$ & $1125-1090$ & 1089 & 1114,1091 & 1114,1091 & $\begin{array}{l}1112 \\
1089\end{array}$ & $\begin{array}{l}1112 \\
1089\end{array}$ \\
\hline Неплоские $\delta$ ОН & $1020-890$ & 1014 & 1014 & 1012 & 1014 & 1014 \\
\hline $\begin{array}{c}\delta_{\text {oop }} \text { C-Н в бензоль- } \\
\text { ном кольце }\end{array}$ & $900-690$ & 817 & 817 & 817 & 817 & 819 \\
\hline$\delta_{\text {oop }} \mathrm{OH}$ & $750-650$ & 721 & 721 & 721 & 723 & 723 \\
\hline $\begin{array}{c}\delta \mathrm{O}=\mathrm{C}-\mathrm{N} \\
(\text { Амид IV) }\end{array}$ & $\sim 620$ & 603 & 603 & 603 & 603 & 603 \\
\hline
\end{tabular}




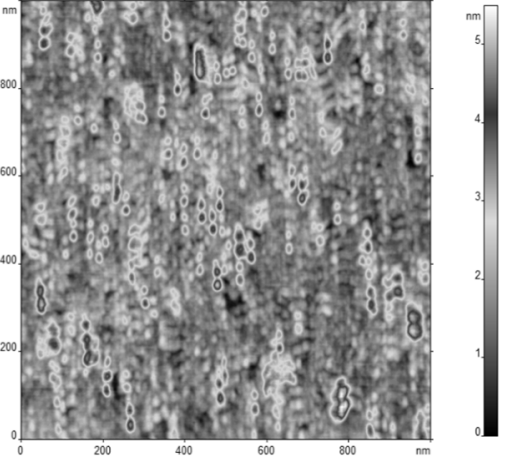

a

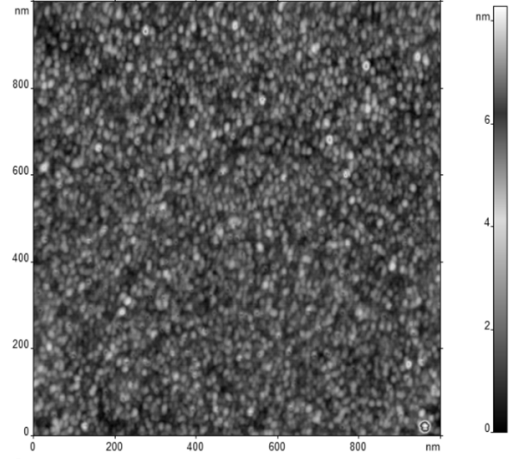

6

Рис. 3. ССМ-изображения поверхностей пьезосенсоров, модифицированных полимерами сравнения: а - нанесение предполимеризационной смеси проводилось шпателем; б - нанесение предполимеризационной смеси проводилось штампованием

Fig. 3. SPM images of the surfaces of piezoelectric sensors modified with reference polymers: a - the prepolymerization mixture was applied with a spatula; $\mathrm{b}$ - the prepolymerization mixture was applied by stamping

Поскольку термоимидизация рассмотренных нами полимеров происходит непосредственно на поверхности электрода сенсора, актуальным считалось исследовать методом сканирующей силовой микроскопии (ССM) поверхность пленок полученных после нанесения предполимеризационных смесей шпателем и штампованием. ССМ-изображения поверхностей пленок представлены на рисунке 3.

Из полученных изображений видно, что пленка полиимида без добавления шаблона имеет однородную поверхность. Пленка, полученная при нанесении предмолимеризационной смеси штампованием, обладает более равномерной поверхностью с перепадом высот от 1.4 до
2.6 нм (содержит $88.94 \%$ пор радиусом до 10 нм), в то время как с использованием шпателя получена пленка с высотами до $4.0 \mathrm{HM}$.

Ранее авторы [20-22] исследовали морфологию пленок, полученных после нанесения шпателем предполимеризационной смеси на сенсор, и был установлен большой разброс по высотам (до 60 нм!), а также высоко развитая шероховатость поверхности.

Нами установлено, что применение штампования позволяет получать пленки с хорошей воспроизводимостью толщины и морфологии поверхности, чем при использовании шпателя. В связи с этим в дальнейшем исследовали только пленки, полученные штампованием.

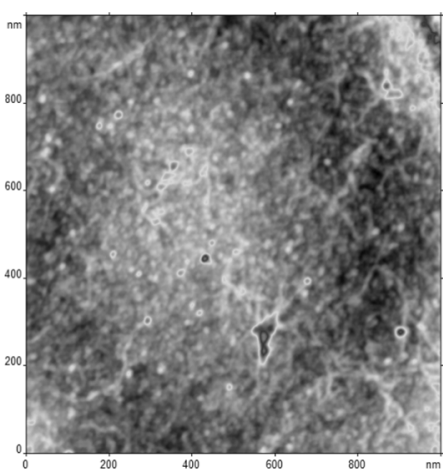

a

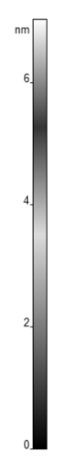

Рис. 4. ССМ-изображения поверхностей пленок полиимида с E202 (a) и молекулярно-импринтированного полимера с отпечатком E202 (б)

Fig. 4. SPM images of surfaces of films of polyimide with E202 (a) and molecularly imprinted polymer with an imprint of E202 (b) 


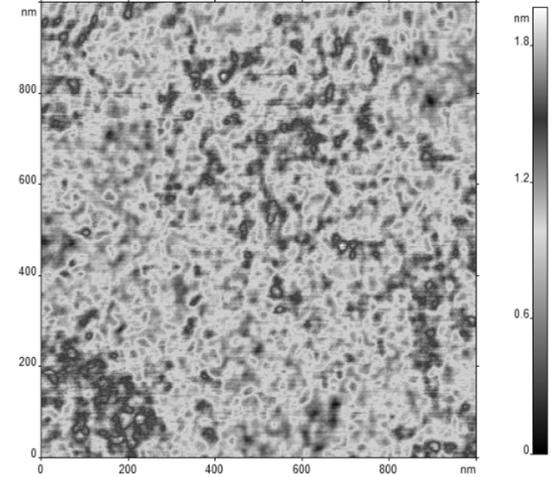

a

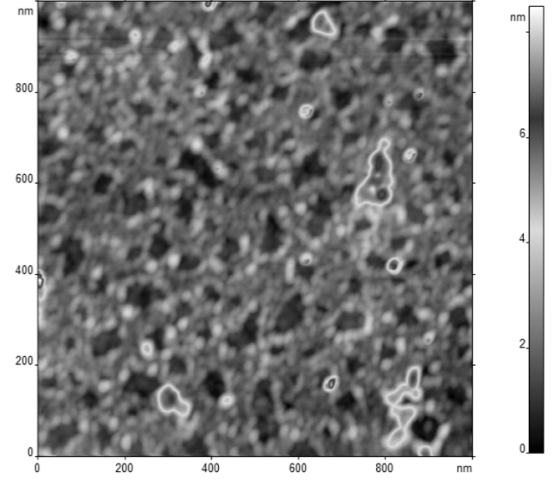

б

Рис. 5. ССМ-изображения поверхностей пленок полиимида с Е211 (a) и молекулярно-импринтированного полимера с отпечатком Е211 (б)

Fig. 5. SPM images of surfaces of films of polyimide with E211 (a) and molecularly imprinted polymer with an imprint of E211 (b)

Таблица 2. Распределение пор в полимерных пленках*

Table 2. Pore distribution in polymer films

\begin{tabular}{|c|c|c|c|c|c|c|}
\hline \multicolumn{2}{|c|}{$\begin{array}{c}\text { Классификация } \\
\text { пор r, нм }\end{array}$} & ПС & П+Е202 & $\begin{array}{c}\text { МИП- } \\
\text { Е202 }\end{array}$ & П+Е211 & $\begin{array}{c}\text { МИП- } \\
\mathrm{E} 211\end{array}$ \\
\cline { 3 - 7 } \multicolumn{2}{|c|}{} & $\mathrm{n}, \%$ & $\mathrm{n}, \%$ & $\mathrm{n}, \%$ & $\mathrm{n}, \%$ & $\mathrm{n}, \%$ \\
\hline ультра- & $<1$ & 9.55 & 6.19 & 8.47 & 9.45 & 4.35 \\
\hline микро- & $1-10$ & 88.94 & 79.13 & 77.16 & 78.65 & 56.52 \\
\hline мезо- & $10-25$ & 1.51 & 14.37 & 13.30 & 10.76 & 22.83 \\
\hline макро- & $25-50$ & 0.00 & 0.31 & 1.07 & 1.14 & 16.30 \\
\hline
\end{tabular}

*ПС - полимер сравнения; П+Е202 и П+Е211 - полиимид с сорбатом калия и бензоатом натрия, соответственно; МИП-Е202 и МИП-Е211 - молекулярно-импринтированный полимер с отпечатками сорбатом калия и бензоатом натрия, соответственно

На рисунках 4 и 5 представлены ССМизображения поверхностей молекулярноимпринтированных полимеров с отпечатками сорбата калия (Е202) и бензоатом натрия (E211).

В полиимиде, не содержащем молекулы-шаблонов, присутствует более $80 \%$ микропор. В результате молекулярного импринтинга происходит перестройка структуры полимеров МИП-Е202 и МИП-Е211, приводящая к уменьшению количества микропор и увеличению количества мезопор (табл. 2).

При синтезе молекулярно-импринтированных полимеров линейная структура сорбата калия позволяет его молекуламшаблонам располагаться на поверхности полимера и заглубляться в его матрицу. После удаления шаблона в полимере остаются полости, которые в идеале должны быть комплементарны по форме, размеру и расположению функциональных групп молекулам-шаблонам [23-25].
В случае с бензоатом натрия количество ультрамикро- и микропор уменьшилось, в то время как количество мезо- и макропор увеличилось. Вероятно, макропоры следует рассматривать как крупные полости, внутри которых возможны углубления и поры (отпечатки) комплементарные молекулам бензоата натрия размеры которых $-0.82 \mathrm{Hм}$.

\section{Заключение}

Структурно-групповой анализ ИКспектров полученных полимеров показал отсутствие значительных изменений в ИК-спектрах МИП и исходного полиимида, что свидетельствует об отсутствии изменений в структуре, но при этом увеличивается интенсивность характеристических полос пропускания для полимеров с отпечатками консервантов.

В работе установлено, что нанесение предполимеризационной смеси методом штампования приводит к формирование 
равномерной поверхности с небольшим перепадом высот. После удаления шаблонов остается высоко развитая пористая поверхность. И отсутствие глобул на по-

\section{Список литературы}

1. Нечаев А.П. Кочеткова А.А., Зайцев А.Н. Пищевые добавки. М. Колос. Колос-Пресс. 2002. $256 \mathrm{c}$.

2. Shazia Khanum Mirza, Asema U.K., Sayyad Sultan Kasim // Journal of Medicinal Chemistry and Drug Discovery. 2017. Vol. 2. No 2. pp. 610-616.

3. Требования безопасности пищевых добавок, ароматизаторов и технологических вспомогательных средств: технический регламент Таможенного союза ТР ТС 029/2012. от 20.07. 2012 г. № 58.

4. Abdulmumeen H.A., Risikat A.N., Sururah A.R. // International Journal of Biological Chemistry. 2012. Vol 1. pp. 36-47.

5. Inetianbor J. E., Ykubu J. M., Ezeonu S. C. // Asian Journal of Science and Technology. 2015. Vol 6. No 2. pp. 1118-1135.

6. Kumar H., Jha A., Taneja K.K., Kabra K. et al. // National Journal of Community Medicine. 2013. Vol. 4. No 3. pp. 402-406.

7. Ree M., Stoa E. // Concordia College Journal of Analytical Chemistry. 2011. Vol. 1. pp. 71-77.

8. Chua S.L., Teo S.S. // International Journal of Nutrition and Food Sciences. 2017. Vol. 2. No 4. pp. 58-64.

9. Майстренко В.Н., Майстренко В.Н., Хамитов Р.3., Будников Г.К. Эколого-аналитический мониторинг супертоксикантов. М. Химия. 1996. 319 с.

10. Зяблов А.Н., Дуванова О.В. и др. Патент РФ. № 137946. 2014.

11. Зяблов А.Н., Дуванова О.В. и др. Патент РФ. № 1138636. 2014.

12. Казицына Л.А., Куплетская Н.Б. Применение УФ, ИК и ЯМР спектроскопии в органической химии. М. Высшая школа. 1971. $264 \mathrm{c}$.

13. Roeges N.P.G. A guide to the complete interpretation of infrared spectra of organic structures. New York. John Wiley \& Sons. 1994. 340 p. верхности молекулярно-импринтированных полимеров свидетельствует о практически полном удалении в процессе экстракции молекул-шаблонов.

14. Scanning Probe Microscopy Image Processing Software «FemtoScan Online». M. Advanced Technologies Center.

15. Углянская В.А. и др. Инфракрасная спектроскопия ионообменных материалов. Воронеж. Издательство Воронежского государственного университета. 1989. 208 с.

16. Silverstein R.M., Webster F.X. Spectrometric Identification of Organic Compounds. New York. John Wiley \& Sons. 1997. 326 p.

17. Тарасевич Б.Н. ИК спектры основных классов органических веществ: справочные материалы. М. МГУ. 2012. 55 с.

18. Шимако Н.А., Шишкина М.В. Инфракрасные ультрафиолетовые спектры поглощения ароматических эфиров. М. Наука. 1987. $125 \mathrm{c}$.

19. Дьяконова О.В., Соколова С.А., Зяблов А.Н., Жиброва Ю.А. // Сорбционные и хроматографические прочессы. 2007. Т. 7. № 5. C. $873-877$.

20. Зяблов А.Н. // Сорбичинные и хроматографические проиессы. 2008. Т. 8. № 1. C. $172-175$.

21. Дьяконова О.В., Зяблов А.Н., Котов В.В., Елисеева Т.В. и др. // Сорбиионные и хроматографические прочессы. 2005. Т. 5. № 4. C. 501-506.

22. Дьяконова О.В., Соколова С.А., Зяблов А.Н., Жиброва Ю.А. // Сорбчионные и хроматографические прочессы. 2008. Т. 8. № 5. С. 863-868.

23. Дуванова О.В., Володина Л.В., Зяблов А.Н., Гречкина М.В. и др. // Сорбиионные и хроматографические проиессы. 2013. Т. 13. № 6. C. 884-890.

24. Гендриксон О.Д., Жердев А.В., Дзантиев Б.Б. // Успехи биологической химии. 2006. Т. 46. С. 149-192.

25. Дмитриенко С.Г., Ирха В.В., Дуйсебаева Т.Б., Михайлик Ю.В. и др. // Журнал аналитической химии. 2006. Т. 61. №1. С.18-23. 


\title{
Analysis of the properties of films of moleculary imprinted polymers based on polyimide
}

\author{
Wu Hoang Yen ${ }^{1,2}$, Khao Nyat Lin $^{3}$, Zyablov A.N. ${ }^{1}$ \\ ${ }^{1}$ Voronezh State University, Voronezh \\ ${ }^{2}$ Ho Chi Minh City Food Industry University, Vietnam \\ ${ }^{3}$ Coastal Branch, Vietnam-Russia Tropical Centre, Vietnam
}

\begin{abstract}
In this study, molecularly imprinted polymers based on a copolymer of 1,2,4,5-benzene tetracarboxylic acid dianhydride with 4,4'-diaminodiphenyl oxide and a solution of preservatives (2:1) were obtained. Study of the properties of molecularly imprinted polymer (MIP) films was performed by infrared spectroscopy and scanning probe microscopy (SPM). It was found that there were no significant differences in the IR spectra of MIP and reference polymers. This means that during the synthesis of molecularly imprinted polymers, the "ladder" structure characteristic of polyimide is retained, but the intensity of the characteristic frequencies for polymers with imprints of preservatives increases.

Analysis of the surface morphology of the films showed that the application of the prepolymerization mixture with a stamp leads to the formation of a more uniform surface (with a height difference from 1.4 to $2.6 \mathrm{~nm}$ ) than in the case when the mixture was applied with a spatula (with heights in the range 0.9-4.0 nm). The developed method of application of the mixture by stamping allowed obtaining films with good reproducibility of thickness and surface morphology.

The comparison of SPM images of molecularly imprinted polymers and the polyimide, on the basis of which they were obtained, revealed a decrease in the number of micropores and an increase in the number of mesopores. In this case, the morphology of MIP-E202 and MIP-E211 films have significant differences associated with the features of the formation of prints of potassium sorbate and sodium benzoate.

During the synthesis of MIP-E211, a significant number of meso- and macropores were formed. Considering the small size of the sodium benzoate molecule $(0.82 \mathrm{~nm})$, it can be assumed that the inner surfaces of the meso- and macropores of the polymer film may contain depressions and pores (imprints) complementary to sodium benzoate molecules. In case of potassium sorbate, which has a linear structure, its molecules were located both on the surface and buried in the polymer matrix. When they were removed, prints, composing the majority of the surface and corresponded to the dimensions of ultramicro- and micropores remained.

The studies of the SPM images of the films of molecularly imprinted polymers revealed the absence of globules on their surface, which indicates the almost complete removal of template molecules during the extraction process.
\end{abstract}

Keywords: sodium benzoate, potassium sorbate, polyimide, molecularly imprinted polymer (MIP), IR spectroscopy, scanning probe microscopy (SPM).

\section{References}

1. Nechayev A.P., Kochetkova A.A., Zaytsev A.N., Pishchevyye dobavki. M., Kolos, KolosPress, 2002, 256 p.

2. Shazia Khanum Mirza, Asema U.K., Sayyad Sultan Kasim, Journal of Medicinal Chemistry and Drug Discovery, 2017, Vol. 02, No 02, pp. 610-616.

3. Trebovaniia bezopasnosti pishchevykh dobavok, aromatizatorov i tekhnologicheskikh vspomogatel'nykh sredstv: tekhnicheskii reglament Tamozhennogo soiuza TR TS 029/2012 of 20.07, 2012, No 58.

4. Abdulmumeen H.A., Risikat A.N., Sururah A.R., International Journal of Biological Chemistry, 2012, Vol 1, pp. 36-47.
5. Inetianbor J.E., Yakubu J.M., Ezeonu S.C., Asian Journal of Science and Technology, 2015, Vol 6, No 2, pp. 1118-1135.

6. Kumar H., Jha A., Taneja K.K., Kabra K. et al, National Journal of Community Medicine, 2013, Vol. 4, No 3, pp. 402-406.

7. Ree M., Stoa E., Concordia College Journal of Analytical Chemistry, 2011, Vol. 1, pp. 71-77.

8. Chua S.L., Teo S.S., International Journal of Nutrition and Food Sciences, 2017, Vol. 2, No 4, pp. 58-64.

9. Maystrenko V.N., Maystrenko V.N., Khamitov R.Z. Budnikov G.K. Ekologo-analiticheskiy monitoring supertoksikantov, M., Khimiya, 1996, $319 \mathrm{p}$.

10. Zyablov A.N., Duvanova O.V. et al. Patent RF, No 137946, 2014. 
11. Zyablov A.N., Duvanova O.V. et al. Patent RF, No 1138636, 2014.

12. Kazitsyna L.A., Kupletskaya N.B. Primeneniye UF, IK i YAMR spektroskopii $\mathrm{v}$ organicheskoy khimii. M., Vysshaya shkola, 1971, $264 \mathrm{p}$.

13. Roeges N.P.G. A guide to the complete interpretation of infrared spectra of organic structures. New York, John Wiley \& Sons, 1994, 340 p.

14. Scanning Probe Microscopy Image Processing Software «FemtoScan Online». M. Advanced Technologies Center.

15. Uglyanskaya V. A. et al. Infrakrasnaya spektroskopiya ionoobmennykh materialov. Voronezh, Izdatel'stvo Voronezhskogo gosudarstvennogo universiteta. 1989, $208 \mathrm{p}$.

16. Silverstein R. M., Webster F. X. Spectrometric Identification of Organic Compounds. New York, John Wiley \& Sons. 1997, p. 326.

17. Tarasevich B. N. IK spektry osnovnykh klassov organicheskikh veshchestv: spravochnyye materialy. Moskva, MGU, 2012. $55 \mathrm{p}$.

18. Shimako N. A., Shishkina M. V. Infrakrasnyye ul'trafioletovyye spektry pogloshcheniya aromaticheskikh efirov. Moskva, Nauka, 1987, 125 p.

Ву Хоанг Иен - аспирант кафедры аналитической химии, Воронежский государственный университет, Воронеж; преподаватель кафедры Менеджмента качества и безопасности пищевых продуктов, Пищевой Промышленный Университет Хошимина, Вьетнам

Као Ньят Линь - к.Х.н., ассистент-исследователь, Приморское отделение, Совместный Российско-Вьетнамский тропический научно-исследовательский и технологический центр, Вьетнам

Зяблов Александр Николаевич - д.Х.Н., профессор кафедры аналитической химии, Воронежский государственный университет, Воронеж
19. D'yakonova O.V., Sokolova S.A., Zyablov A.N., Zhibrova Yu.A., Sorbtsionnye i khromatograficheskie protsessy, 2007, Vol. 7, No. 5, pp. 873-877.

20. Zyablov A.N., Sorbtsionnyye i khromatograficheskiye protsessy, 2008, Vol. 8, No 1, pp. 172-175.

21. D'yakonova O.V., Zyablov A.N., Kotov V.V., Yeliseyeva T.V. et al., Sorbtsionnyye $i$ khromatograficheskiye protsessy, 2005, Vol. 5, No 4, pp. 501-506.

22. D'yakonova O.V., Sokolova S.A., Zyablov A.N., Zhibrova Yu.A., Sorbtsionnyye i khromatograficheskiye protsessy, 2008, Vol. 8, No 5, pp. 863-868.

23. Duvanova O.V., Volodina L.V., Zyablov A.N., Grechkina M.V. et al., Sorbtsionnye $i$ khromatograficheskie protsessy, 2013, Vol. 13, No 6, pp. 884-890.

24. Gendrikson O.D., Zherdev A.V., Dzantiyev B.B., Uspekhi biologicheskoy khimii, 2006, Vol. 46, pp. 149-192.

25. Dmitriyenko S.G., Irkha V.V., Duysebayeva T.B., Mikhaylik Yu.V. et al., Zhurnal analiticheskoy khimii, 2006, Vol. 61, No 1, pp. 18-23.

Vu Hoang Yen - postgraduate student, department of analytical chemistry, Voronezh State University, Voronezh; Lecturer Department of Food Safety and Quality Management, Ho Chi Minh City University of Food Industry, Vietnam, e-mail: yenvh@hufi.edu.vn

Cao Nhat Linh - PhD in Chemistry, Research assistant, Coastal Branch, Vietnam-Russia Tropical Centre, Vietnam. e-mail: cnlinh0812@gmail.com

Zyablov Alexander N. - Dr.Sci. (Chemistry), professor, department of analytical chemistry, Voronezh State University, Voronezh. e-mail: alex-nz@yandex.ru 